\title{
Beta1 integrin blockade overcomes doxorubicin resistance in human T-cell acute lymphoblastic leukemia
}

\author{
Sofiane Berrazouane ${ }^{1}$, Marc Boisvert ${ }^{1}$, Suzanne Salti ${ }^{2}$, Walid Mourad ${ }^{2}$, Reem Al-Daccak ${ }^{3}$, Frédéric Barabé ${ }^{1,4}$ and \\ Fawzi Aoudjit,
}

\begin{abstract}
Growing evidence indicates that cell adhesion to extracellular matrix (ECM) plays an important role in cancer chemoresistance. Leukemic T cells express several adhesion receptors of the $\beta 1$ integrin subfamily with which they interact with ECM. However, the role of $\beta 1$ integrins in chemoresistance of T-cell acute lymphoblastic leukemia (T-ALL) is still ill defined. In this study, we demonstrate that interactions of human T-ALL cell lines and primary blasts with three-dimensional matrices including Matrigel and collagen type I gel promote their resistance to doxorubicin via $\beta 1$ integrin. The blockade of $\beta 1$ integrin with a specific neutralizing antibody sensitized xenografted CEM leukemic cells to doxorubicin, diminished the leukemic burden in the bone marrow and resulted in the extension of animal survival. Mechanistically, Matrigel/ $\beta 1$ integrin interaction enhanced T-ALL chemoresistance by promoting doxorubicin efflux through the activation of the $A B C C 1$ drug transporter. Finally, our findings showed that Matrigel/ $\beta 1$ interaction enhanced doxorubicin efflux and chemoresistance by activating the FAK-related proline-rich tyrosine kinase 2 (PYK2) as both PYK2 inhibitor and siRNA diminished the effect of Matrigel. Collectively, these results support the role of $\beta 1$ integrin in T-ALL chemoresistance and suggest that the $\beta 1$ integrin pathway can constitute a therapeutic target to avoid chemoresistance and relapsed-disease in human T-ALL.
\end{abstract}

\section{Introduction}

Acute T cell lymphoblastic leukemia (T-ALL) accounts for approximately $15 \%$ of all childhood acute leukemia and $25 \%$ of adult ALLs. Although chemotherapy has improved the treatment of T-ALL, the prognosis of drug resistant and relapsed T-ALL remains very poor ${ }^{1}$. Thus, defining the factors promoting T-ALL chemoresistance is critical to improve this prognosis.

The major development site for T-ALL is the bone marrow where the osteoblastic (endosteal) and vascular niches regulate the fate of normal and transformed

\footnotetext{
Correspondence: Fawzi Aoudjit (fawzi.aoudjit@crchudequebec.ulaval.ca) ${ }^{1}$ Division of Immune and Infectious Diseases, CHU de Québec-Université Laval Research Center, Quebec city, Canada

${ }^{2} \mathrm{CHUM}$ Research Center and Faculty of Medicine, Université de Montréal, Montreal, Canada

Full list of author information is available at the end of the article. Edited by M. Diederich
}

hematopoietic cells ${ }^{2,3}$. These two niches are rich in adhesive substrates particularly the extracellular matrix (ECM). Normal and malignant hematopoietic cells express several adhesion receptors among which, is the $\beta 1$ integrin subfamily that mediates their interactions with stromal cells and ECM. The $\beta 1$ integrins are $\alpha / \beta$ heterodimeric membrane receptors, which upon ligand binding induce activation of non-receptor tyrosine kinases including focal adhesion kinase (FAK) and its homologous FAK-related proline-rich tyrosine kinase 2 (PYK2) leading to cytoskeletal rearrangements and downstream signaling ${ }^{4}$.

Cell adhesion to stromal cells and ECM plays an important role in the development of chemoresistance ${ }^{5-7}$. In hematological malignancies, the integrin $\alpha 4 \beta 1$, upon binding to its counter-receptor, the vascular cell adhesion molecule1 or to fibronectin, has been implicated in the chemoresistance of myeloma ${ }^{8-10}$ and B cell malignancies ${ }^{11-13}$ whereas,

\section{(c) The Author(s) 2019}

(c) (i) Open Access This article is licensed under a Creative Commons Attribution 4.0 International License, which permits use, sharing, adaptation, distribution and reproduction c. in any medium or format, as long as you give appropriate credit to the original author(s) and the source, provide a link to the Creative Commons license, and indicate if changes were made. The images or other third party material in this article are included in the article's Creative Commons license, unless indicated otherwise in a credit line to the material. If material is not included in the article's Creative Commons license and your intended use is not permitted by statutory regulation or exceeds the permitted use, you will need to obtain permission directly from the copyright holder. To view a copy of this license, visit http://creativecommons.org/licenses/by/4.0/. 
binding to fibronectin through integrins $\alpha 4 \beta 1$ and $\alpha 5 \beta 1$ has been associated with the chemoresistance of myeloid leukemia $^{14-16}$.

T-ALL cells express several $\beta 1$ integrin receptors with which they interact with various ECM proteins including collagens, fibronectin and laminins ${ }^{17,18}$. In this context, collagen type I, via $\alpha 2 \beta 1$ integrin, has been shown to promote T-ALL chemoresistance ${ }^{19}$. Similarly, crosslinking of $\alpha 4 \beta 1$ and $\alpha 5 \beta 1$ integrins with recombinant fibronectin-derived ligands equally enhances T-ALL chemoresistance $^{20}$. Both fibronectin and collagen type I are enriched in the endosteal niche of the bone marrow ${ }^{21}$. However, T-ALL cells also interact with the vascular niche ${ }^{22,23}$, which is enriched in laminins and collagen type IV, but the role of the vascular niche in T-ALL chemoresistance has not been determined.

The above studies on T-ALL chemoresistance were conducted with two-dimensional (2D) matrix models whereas the cells in their niches are likely interacting with a three-dimensional (3D)-organized matrix, which has different signaling properties than the 2D matrix models, raising the issue of whether $\beta 1$ integrin-mediated chemoresistance could be recapitulated with a $3 \mathrm{D}$ matrix. In addition, it remains undetermined if targeting $\beta 1$ integrin could improve chemotherapy and constitutes a therapeutic target in T-ALL.

In this study, we found that attachment to Matrigel, a 3D matrix model mimicking ECM of the vascular niche, promotes T-ALL chemoresistance via $\beta 1$ integrin. In addition, $\beta 1$ integrin blockade sensitized xenografted leukemic cells to chemotherapy and resulted in prolonged animal survival. Finally, our results showed that $\beta 1$ integrin enhanced chemoresistance by activating drug efflux in a PYK2-dependant manner. Collectively our findings suggest that the $\beta 1$ integrin pathway could represent a new therapeutic target to avoid chemoresistance and relapsed-disease in human T-ALL.

\section{Results}

\section{Matrigel protects T-ALL cell lines from doxorubicin-} induced apoptosis

To examine the implication of the ECM present in the vascular niche and the role of a $3 \mathrm{D}$ matrix in T-ALL chemoresistance, we studied the effect of Matrigel on drug-induced apoptosis in human T-ALL cell lines (CEM, Jurkat, HSB2 and Molt-3), which express variable levels of $\alpha$ integrins and high levels of the $\beta 1$ integrin chain ${ }^{17}$. Attachment of various T-ALL cell lines to Matrigel reduced their apoptosis induced upon exposure to doxorubicin (Fig. 1a-d). The best inhibitory effect was observed in CEM and Jurkat $\mathrm{T}$ cell lines where druginduced apoptosis is reduced by $30-40 \%$. To confirm the anti-apoptotic effect of Matrigel, we determined its effect on doxorubicin-induced caspase- 3 activation, which is a main apoptotic event in drug-induced apoptosis. The results show that doxorubicin activates caspase- 3 as determined by the proteolysis of procaspase- 3 and the appearance of active caspase- 3 fragments, and culture of CEM cells on Matrigel significantly reduced doxorubicininduced caspase- 3 activation (Fig. 1e).

We then conducted clonogenic survival assays to evaluate if Matrigel promoted long-term survival. As shown, treatment of the cells with doxorubicin led to the formation of very few colonies (Fig. 1f). However, the presence of Matrigel, which inhibited doxorubicin-induced apoptosis, led in the four $\mathrm{T}$ cell lines, to a remarkable increase in the number of colonies compared to doxorubicin-treated samples. In line with the apoptosis data, the number of colonies induced by Matrigel is higher in CEM and Jurkat than in Molt-3 and HSB2 T cell lines (Fig. 1f). To assess if the role of Matrigel is mediated via $\beta 1$ integrins, we tested the effect of the well-characterized human $\beta 1$ integrinspecific blocking $\mathrm{mAb}$, AIIB2, which has been shown to block tumor cell-interactions with 3D matrices including Matrigel $^{24,25}$. Addition of AIIB2 substantially reduced the Matrigel effect on colony formation (Fig. 1f), indicating the implication of $\beta 1$ integrin in chemoresistance. In addition to Matrigel, $\beta 1$ integrin also mediates the protective effect of collagen type I gel; an additional 3D matrix model (Supplementary Fig. 1).

\section{Matrigel protects primary T-ALL blasts from doxorubicin- induced apoptosis}

To determine if the findings with T-ALL cell lines occur in a clinical setting, we assessed the expression of $\beta 1$ integrin and the effect of Matrigel in primary T-ALL blasts. Three different T-ALL samples expressing surface CD3 originating from the blood of patients at diagnosis were obtained and analyzed for their expression of $\beta 1$ integrin. $\beta 1$ integrin is highly expressed in all samples; between 92 and $99 \%$ of total cells expressed $\beta 1$ (Fig. 2a). Similar to T-ALL cell lines, attachment to Matrigel reduced doxorubicin-induced apoptosis in T-ALL blasts (Fig. 2b). Importantly, the protective effect of Matrigel was reversed by the $\beta 1$ integrin blocking mAb AIIB2 (Fig. 2b). As a control, AIIB2 had no effect on the survival of cells cultured in medium or in the presence of Matrigel. Thus, 3D matrices promote doxorubicin resistance of both human T-ALL cell lines and primary T-ALL blasts via $\beta 1$ integrin.

\section{Blockade of $\beta 1$ integrin sensitizes human T-ALL xenograft to chemotherapy}

To examine whether the role of $\beta 1$ integrin is relevant in vivo, we tested the effect of the human $\beta 1$ integrinspecific blocking $\mathrm{mAb}$, AIIB2, in the human T-ALL CEM xenograft model $^{26,27}$. In addition, AIIB2 has been shown to block $\beta 1$ integrin in various tumor cell models in vivo ${ }^{24,25}$. 

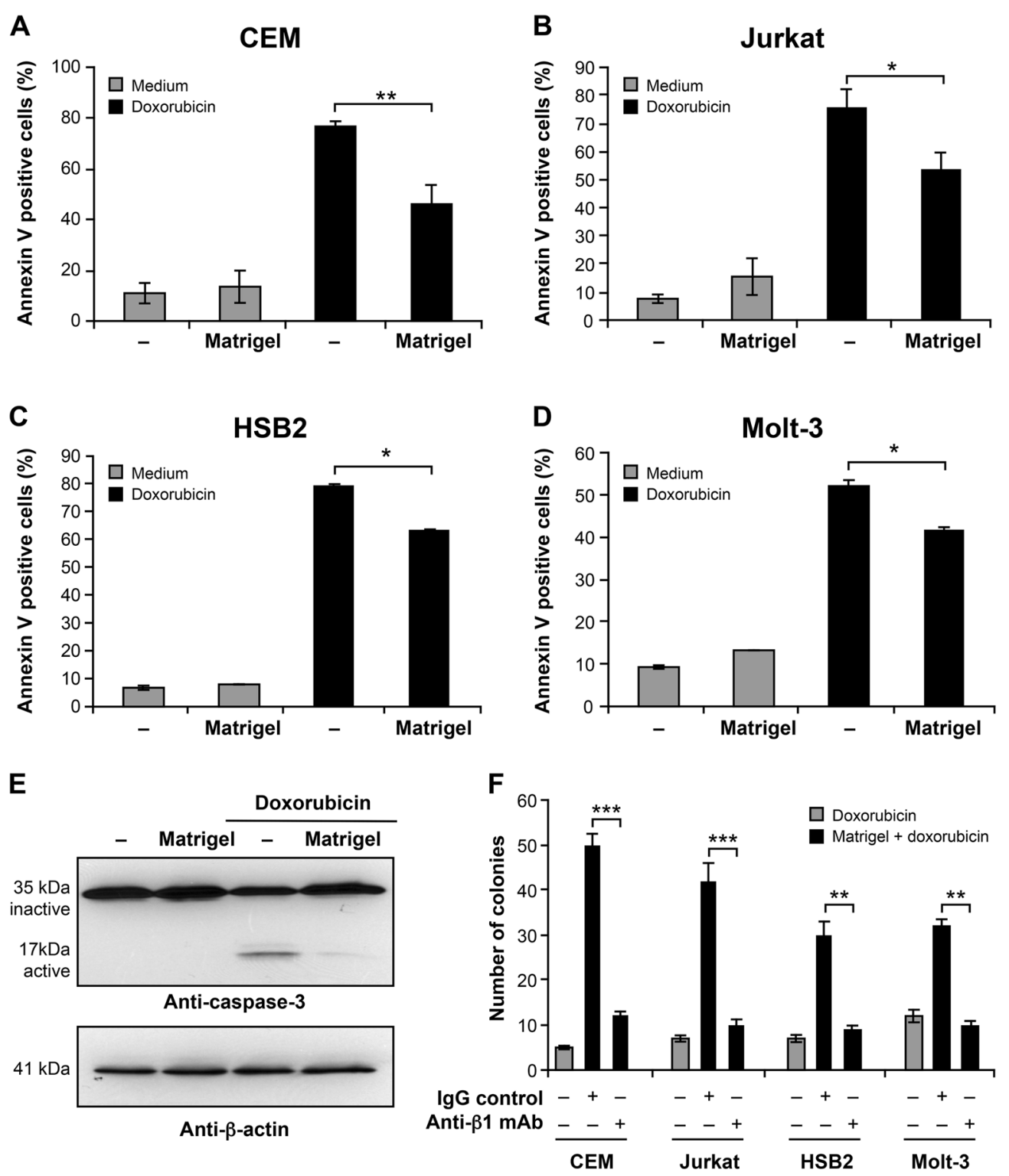

Fig. 1 Attachment to Matrigel promotes doxorubicin resistance of T-ALL cell lines through $\boldsymbol{\beta} 1$ integrin. CEM a, Jurkat $\mathbf{b}, H S B-2$ c, Molt-3 $\mathbf{d}$ were cultured on plastic (-) or on Matrigel for $4 \mathrm{~h}$ and then treated or not with doxorubicin. After $24 \mathrm{~h}$, apoptosis was analyzed by annexin $\mathrm{V}$ staining and flow cytometry. e Matrigel inhibits doxorubicin-induced caspase-3 activation. CEM cells were cultured on Matrigel or on plastic (-) and then treated or not with doxorubicin for $12 \mathrm{~h}$. Cells were lysed and cell lysates subjected to immunoblot analysis with an anti-caspase-3 antibody. The blot was stripped and reprobed with anti- $\beta$-actin antibody for equal loading. The blot is representative of three independent experiments. $\mathbf{f}$ Matrigel promotes clonogenic growth via $\beta 1$ integrin. Clonogenic growth of T-ALL cell lines was determined in the presence of $10 \mu \mathrm{g} / \mathrm{ml}$ of control $\mathrm{lgG}$ or anti-human $\beta 1$ integrin blocking mAb (AllB2), which were added before seeding the cells on Matrigel. Results represent the mean values \pm S.D. of three independent experiments. ${ }^{*} P<0.05 ;{ }^{* *} P<0.01 ;{ }^{* *} P<0.001$

Thus, we first assessed leukemia growth by flow cytometry using the marker CD5, which is highly expressed on CEM cells ${ }^{26,27}$. Mice-bearing leukemia were treated with control IgG, AIIB2, IgG + doxorubicin or AIIB2 + doxorubicin (Fig. 3a). Treatment with AIIB2 alone had no effect on the number of leukemic cells $\left(\mathrm{CD} 5^{+}\right)$in the bone marrow (Fig. 3b). However, doxorubicin in the presence of a control IgG reduced leukemic load by approximately
30\% (Fig. 3b). More importantly, the addition of AIIB2 significantly enhanced the effect of doxorubicin leading to $60 \%$ reduction in leukemic cell numbers compared to control IgG-treated mice (Fig. 3b). In contrast to the bone marrow, AIIB2 alone and in combination with doxorubicin inhibited tumor growth in the spleen (Fig. 3c).

We then examined whether treatment with AIIB2 will result in the extension of animal survival. Treatment of 

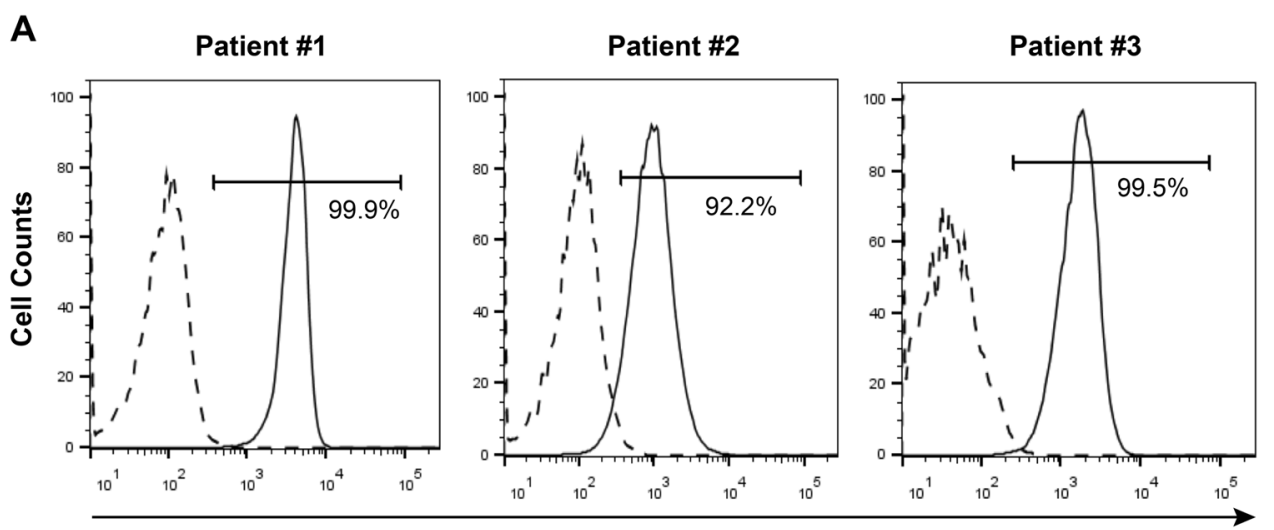

Fluorescence

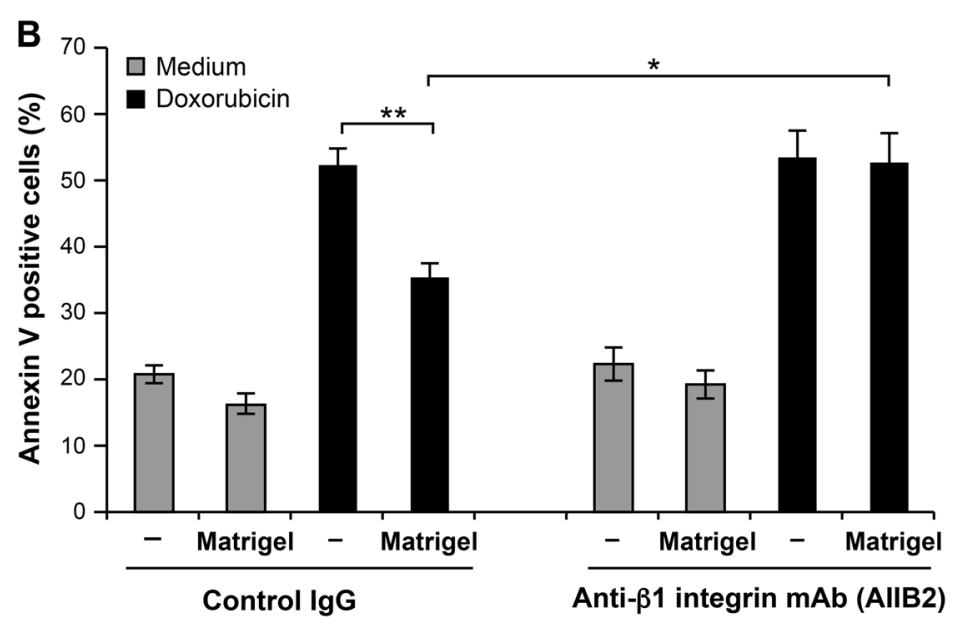

Fig. 2 Matrigel/ $\beta 1$ integrin promotes doxorubicin resistance of primary T-ALL blasts. a Flow cytometry expression of $\beta 1$ integrin chain on three different T-ALL blasts. The percentage of positive cells is indicated. $\mathbf{b} \beta 1$ integrin mediates the protective effect of Matrigel. Primary T-ALL blasts were cultured on Matrigel in the presence of $10 \mu \mathrm{g} / \mathrm{ml}$ of control lgG or anti- $\beta 1$ integrin blocking mAb (AllB2) and then treated for $24 \mathrm{~h}$ with doxorubicin. Apoptosis was analyzed by annexin $\vee$ staining and flow cytometry. Results represent the mean values \pm S.D. obtained with blasts from three different T-ALL patients. ${ }^{*} P<0.05 ;{ }^{*} P<0.01$

mice with AIIB2 alone had a marginal and a nonsignificant effect $(P=0.3)$ on their survival time compared to control IgG-treated mice (Fig. 3d). Similarly, treatment with doxorubicin also had a minor effect compared to control animals but was not significant $(P=0.3)$. However, treatment with doxorubicin + AIIB2 significantly extended the survival of leukemic mice compared to other treatment groups (Fig. 3d). The mean survival time of the doxorubicin + AIIB2 group is 34.8 vs 26.2 days for the control IgG group $(P<0.001)$. Interestingly, all animals in the doxorubicin + AIIB2 group had their survival time prolonged.

Treatment with AIIB2 did not affect weight loss of leukemic mice (Fig. 3e) suggesting that it did not exacerbate the burden of leukemia or the toxic effect of doxorubicin.

Finally, since AIIB2 might cross-react with mouse $\beta 1$ integrin, we sought to determine whether its sensitizing effect was due to its action on $\beta 1$ integrin expressed by mouse bone marrow cells. To test this possibility, we assessed the effect of a mouse $\beta 1$ integrin blocking $\mathrm{mAb}$ $(\mathrm{Ha} 2 / 5)$. The results showed that treatment of leukemic mice with this antibody alone and in combination with doxorubicin had no effect on animal survival (Supplementary Fig. 2) suggesting that it did not sensitize xenografted leukemic cells to the effect of doxorubicin. Taken together, these results indicate that targeting $\beta 1$ integrin overcomes doxorubicin resistance of leukemic cells in vivo by acting on leukemic cells.

\section{Matrigel/ $\beta 1$ integrin enhances doxorubicin efflux}

After demonstrating the role of $\beta 1$ integrin in T-ALL chemoresistance, we examined the mechanisms by which $\beta 1$ integrin promotes chemoresistance. One major mechanism accounting for drug resistance in cancer cells is the decrease in intracellular drug concentrations via the 
A

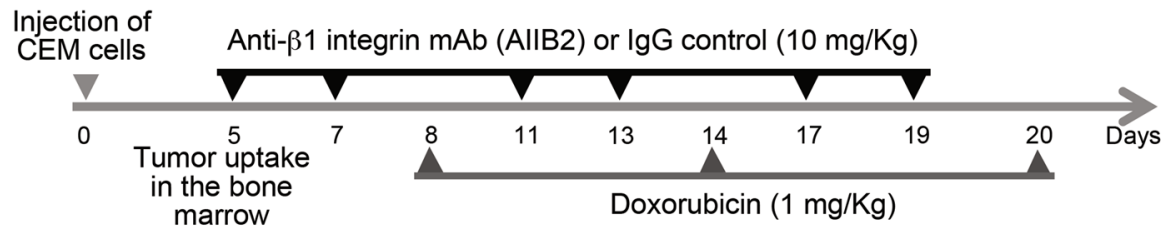

B
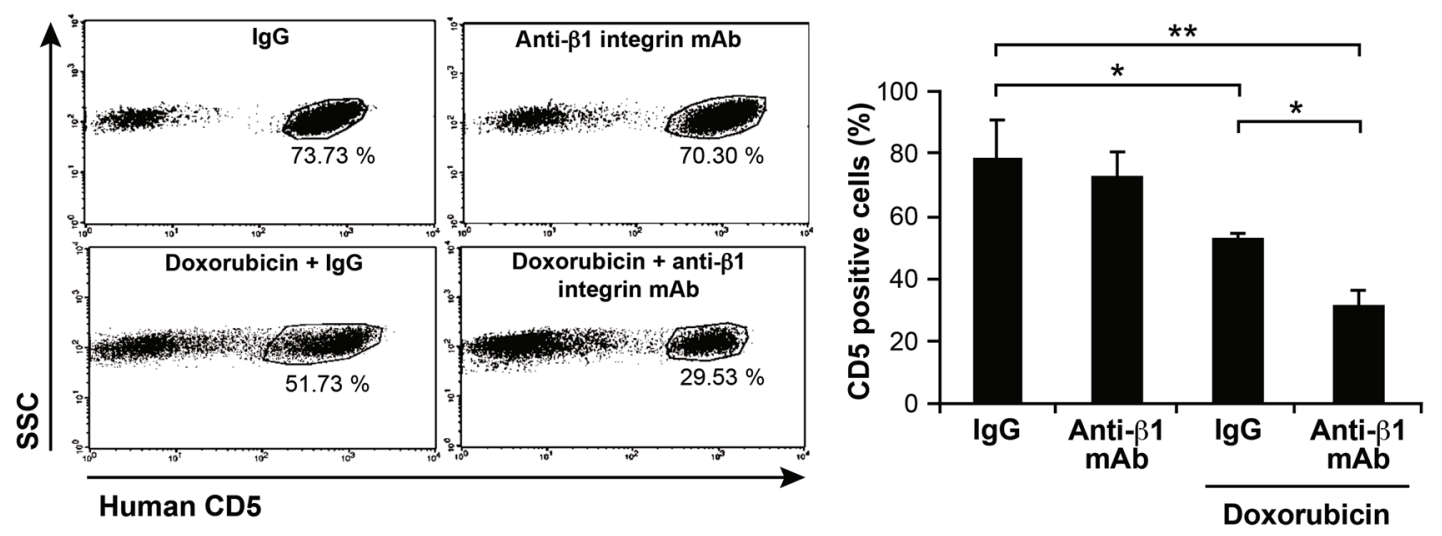

C

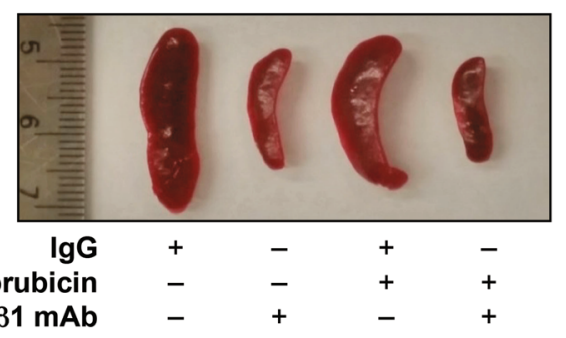

D
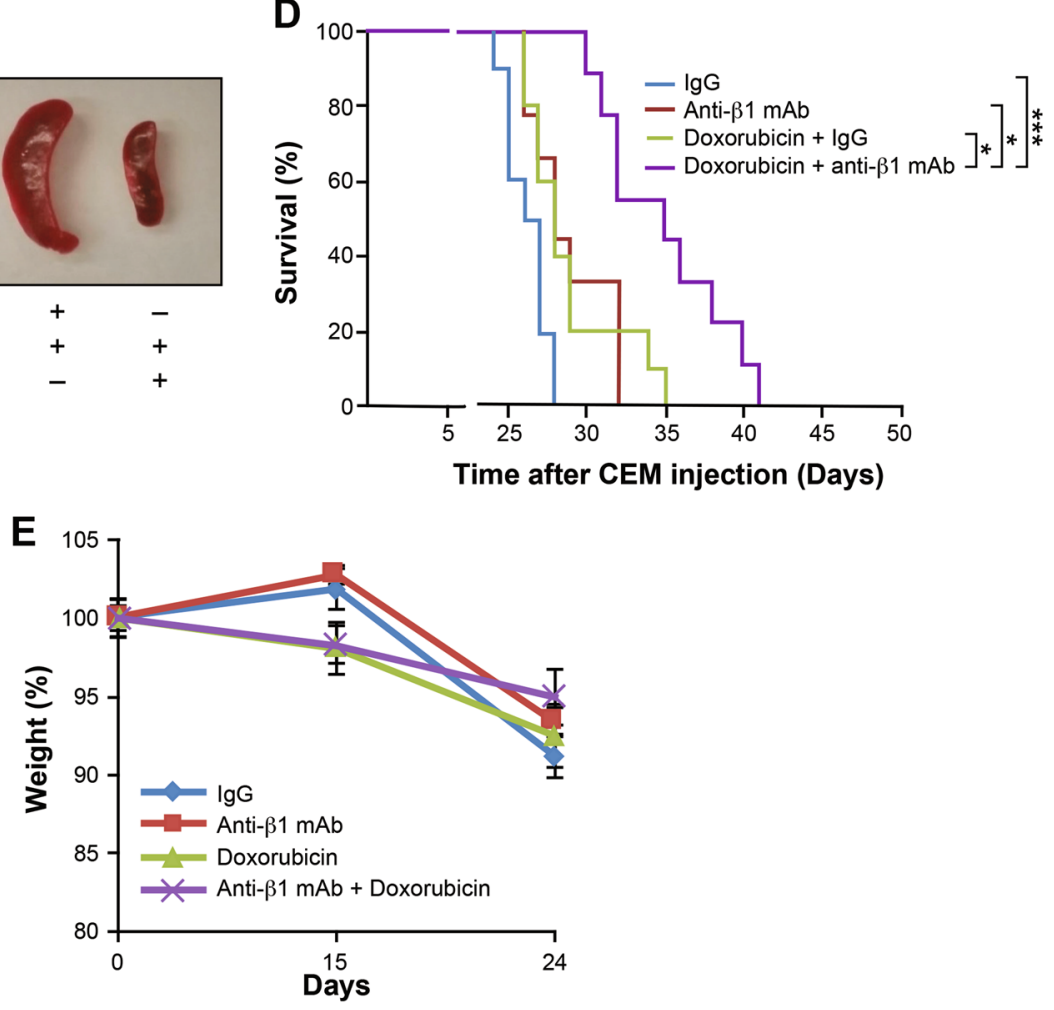

Fig. $3 \boldsymbol{\beta} 1$ integrin promotes T-ALL resistance to doxorubicin in vivo. a Scheme of animal protocol. $\mathbf{b}$ The blocking anti-human $\beta 1$ integrin mAb (AllB2) sensitizes xenotransplanted CEM cells to doxorubicin. Leukemic mice were treated as indicated, and at day 19, bone marrow cells were recovered from sacrificed mice, stained with PE-conjugated anti-human CD5 mAb and analyzed by flow cytometry. Representative FACS profiles (left panel) showing numbers of $\mathrm{CD}^{+}$cells in the bone marrow. The histogram (right panel) represents quantification of $\mathrm{CD}^{+}$cells numbers in the bone marrow ( $n=6$ mice/group). c Representative spleens recovered from leukemic mice at day 28. $\mathbf{d}$ Kaplan-Meyer analysis of animal survival in the different experimental groups ( $n=9-10$ per group). e Variation in animal weights across the four treatment groups. Results represent the mean values \pm S.D. of two independent experiments. ${ }^{*} P<0.05 ;{ }^{*} P<0.01$; ${ }^{* *} P<0.001$ 
A

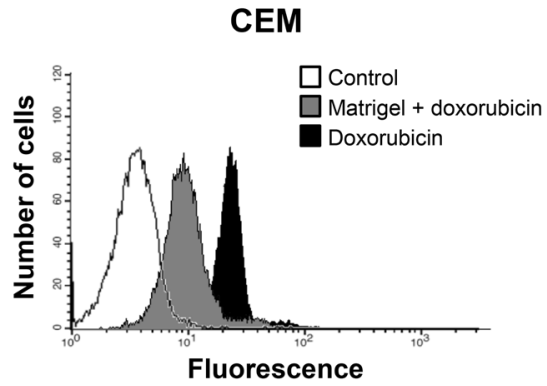

B

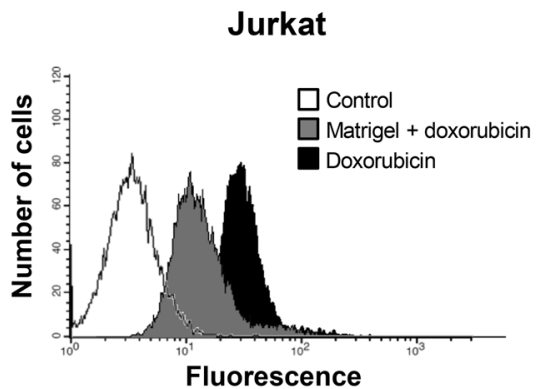

C

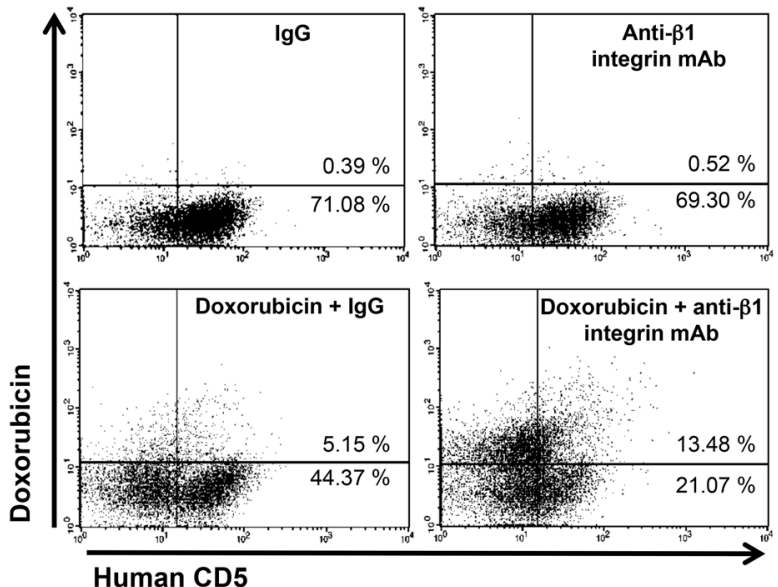

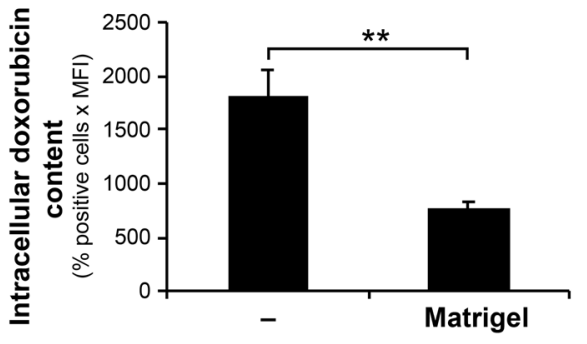
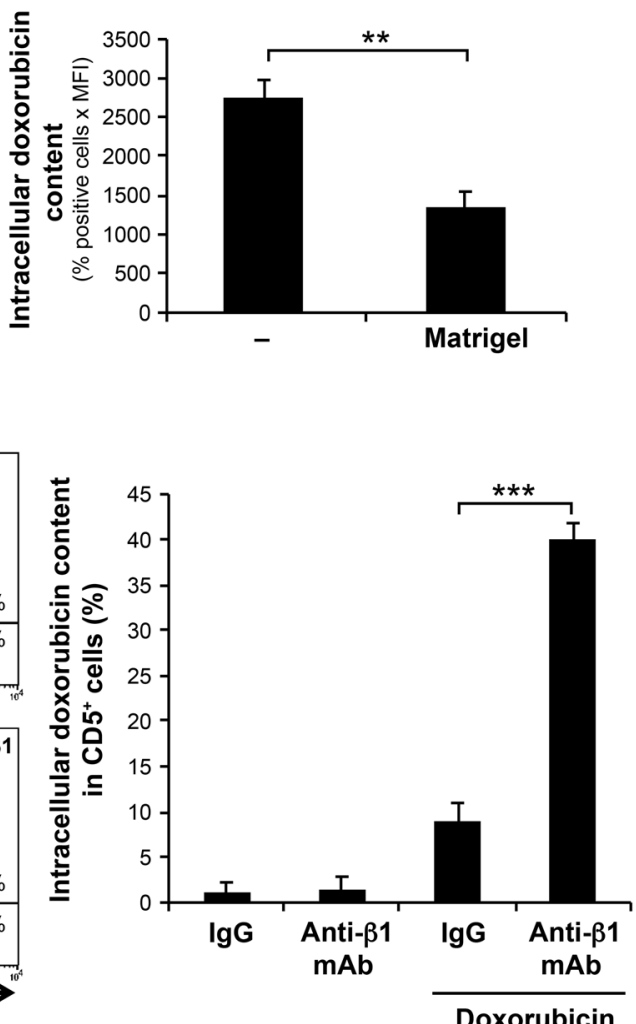

Fig. 4 Matrigel/ $\beta 1$ integrin promotes doxorubicin efflux. Matrigel reduces doxorubicin intracellular content in human T-ALL cell lines. CEM a and Jurkat $\mathbf{b}$ were cultured on Matrigel or on plastic (-) for $4 \mathrm{~h}$ and then treated with doxorubicin for $2 \mathrm{~h}$. The cells were washed and analyzed by flow cytometry. Representative FACS profiles (left panels) showing intracellular doxorubicin content. The histograms (right panels) represent quantification of intracellular doxorubicin content. c Blockade of $\beta 1$ integrin with the anti- $\beta 1$ integrin mAb (AllB2) increases intracellular doxorubicin content in xenotransplanted CEM cells. Leukemic mice were treated as indicated and sacrificed one day after the last injection of doxorubicin (day 21). Bone marrow cells were recovered from leukemic mice $(n=6)$, stained with Alexa-647 conjugated anti-human CD5 mAb and analyzed by flow cytometry. Representative FACS profiles (left panel) showing intracellular doxorubicin content. The histogram (right panel) represents quantification of intracellular doxorubicin content in the $\mathrm{CD}^{+}$cell population. Results represent the mean values \pm S.D. from two (panel $\mathrm{C}$, right panel) and three (panels A\&B) independent experiments. ${ }^{* *} P<0.01 ;{ }^{* *} P<0.001$

activation of drug efflux, which is mediated by several membrane drug transporters that belong to the ATPbinding cassette $(\mathrm{ABC})$ superfamily ${ }^{28}$. To test this possibility, we first assessed if Matrigel would reduce intracellular doxorubicin content. The results show that the culture of T-ALL cell lines on Matrigel reduces by $60 \%$ the intracellular doxorubicin content in CEM and Jurkat cells (Fig. 4a, b). We then determined if a similar mechanism occurs in vivo upon treatment with the $\beta 1$ integrin blocking mAb AIIB2. Mice were treated with doxorubicin and antibodies, sacrificed at day 21 , and bone marrow cells were harvested one day after treatment with doxorubicin. We found that leukemic cells $\left(\mathrm{CD}^{+}\right)$harvested from bone marrow of mice treated with doxorubicin + control IgG had a low level of intracellular doxorubicin as only $10 \%$ of the leukemic cells were 
fluorescent (Fig. 4c). However, treatment of mice with doxorubicin + AIIB2 led to approximately $40 \%$ of leukemic cells that contain doxorubicin (Fig. 4c) indicating that blocking $\beta 1$ integrin in vivo sensitized the cells towards more doxorubicin accumulation. Similar results were obtained when quantification of intracellular doxorubicin content was expressed as (\% positive cells $\times$ MFI) (Supplementary Fig. 3).

\section{$A B C C 1$ mediates Matrigel/ $\beta 1$ integrin-induced doxorubicin efflux and resistance in T-ALL cells}

There are two $\mathrm{ABC}$ transporters namely ABCB1 (Pg-P) and $\mathrm{ABCC} 1$ (MRP-1) that are known to play a major role in doxorubicin efflux. Previous studies have shown that human T-ALL cell lines express ABCC1 but not $\mathrm{ABCB} 1^{29,30}$. In agreement, we did not detect the expression of $\mathrm{ABCB} 1$ and Matrigel or doxorubicin did not upregulate $\mathrm{ABCB} 1$ levels (data not shown). However, we found that around $50 \%$ of CEM and $80 \%$ of Jurkat cells express ABCC1 (Fig. 5a). The results also showed that $\mathrm{ABCC} 1$ levels in CEM and Jurkat $\mathrm{T}$ cells lines were not significantly affected by Matrigel or by doxorubicin.

To examine whether $A B C C 1$ is involved in doxorubicin efflux, we evaluated the effect of two specific ABCC1 inhibitors namely MK571 and reversan. The results show that both inhibitors almost completely abolished the effect of Matrigel on intracellular doxorubicin content (Fig. 5b) and the protective effect of Matrigel on doxorubicininduced apoptosis (Fig. 5c). For further support, we studied the effect of Matrigel on vincristine, a known substrate of ABCC1. Matrigel also reduced vincristineinduced apoptosis in CEM $\mathrm{T}$ cell line and the $\mathrm{ABCC} 1$ inhibitor MK571 reversed this effect suggesting the implication of ABCC1 (Supplementary Fig. 4). Together these data indicate that $A B C C 1$ plays a major role in $\beta 1$ integrin-induced drug efflux and chemoresistance in human T-ALL cells.

\section{Matrigel/ $\beta 1$ integrin promotes doxorubicin resistance via PYK2}

Growing evidence suggests that the related-focal adhesion kinase, PYK2, which is known to be downstream of integrins and associated with $\mathrm{T}$ cell signaling, plays a major role in cancer. Accordingly, we studied its implication in cell adhesion-mediated T-ALL chemoresistance. We found that Matrigel increased by 2 to 3 fold the phosphorylation of PYK2 in both CEM and Jurkat T-ALL cell lines (Fig. 6a, b). PYK2 phosphorylation was detected after $15 \mathrm{~min}$ and peaked between $30 \mathrm{~min}$ to $1 \mathrm{~h}$.

We then investigated the implication of PYK2 in the observed chemoresistance by determining the effect of a dual PYK2/FAK inhibitor, VS-6063 in CEM cells. We found that VS-6063 inhibited the effect of Matrigel on doxorubicin efflux as the intracellular doxorubicin content in Matrigel-activated CEM cells cultured in the presence of VS-6063 was similar to that observed in cells cultured on plastic (Fig. 6c). Furthermore, VS-6063 also inhibited the ability of Matrigel to reduce doxorubicininduced apoptosis (Fig. 6d). However, VS-6063 has not affected the survival of CEM cells cultured in medium or in the presence of Matrigel. As expected, VS-6063 inhibited Matrigel-induced PYK2 activation in CEM cells (Fig. 6e). Collectively these results suggest that PYK2 is critical for Matrigel-induced doxorubicin resistance in T-ALL cells.

Since PYK2 inhibitors could have off-target effects, we wished to confirm the implication of PYK2 by performing a PYK2 knockdown. Transfection of Jurkat T cells with a PYK2 specific siRNA reduced the levels of PYK2 compared to control siRNA-transfected Jurkat $\mathrm{T}$ cells (Fig. 7a) (approximately $65-70 \%$ reduction; average of three experiments). Importantly, compared to control siRNA, PYK2 siRNA significantly inhibited the ability of Matrigel to reduce intracellular doxorubicin content (Fig. 7b) and to protect Jurkat $\mathrm{T}$ cells from doxorubicin-induced apoptosis (Fig. 7c). These results indicate that Matrigel/ $\beta 1$ integrin promotes doxorubicin chemoresistance via PYK2.

\section{Discussion}

Understanding the mechanisms underlying cancer chemoresistance is likely to lead to more effective therapies and to a better control of patient relapse. In this study, we report that blockade of the $\beta 1$ integrin cell adhesion molecule overcomes T-ALL doxorubicin resistance by activating its efflux via PYK2.

Our results showed that T-ALL cells are capable of interacting via $\beta 1$ integrins with $3 \mathrm{D}$ matrix proteins Matrigel and collagen type I gel to enhance their resistance to chemotherapy. Matrigel, which contains laminins, collagen IV and proteoglycans mimics the ECM present in the vascular niche, whereas collagen type I is enriched in the endosteal niche. It has been reported that during T-ALL progression, leukemic cells engage in dynamic interactions with bone marrow microenvironment components present in both the endosteal and vascular niches ${ }^{31}$. This is in line with our results and indicates that both niches can provide signals via $\beta 1$ integrins to support T-ALL chemoresistance. Although we were limited in the number of primary T-ALL blasts, our results showed that Matrigel- $\beta 1$ integrin-mediated chemoresistance also occurs in human T-ALL.

The blockade of $\beta 1$ integrin with the specific neutralizing mAb AIIB2 sensitized CEM-xenografted cells to doxorubicin and resulted in the extension of animal survival. Although doxorubicin reduced bone marrow tumor load by $30 \%$, it had only a minor effect on animal survival suggesting that xenotransplanted CEM cells have 
A
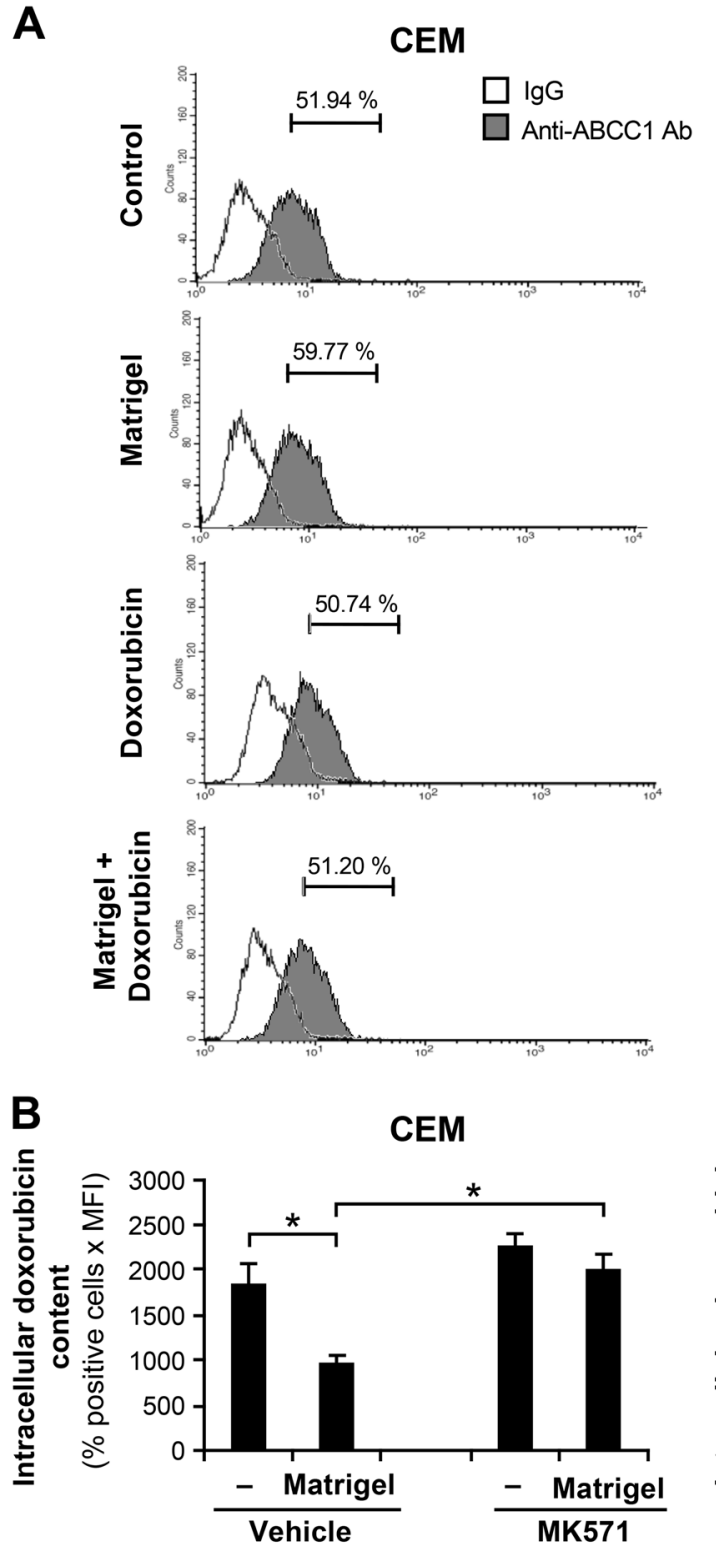

C

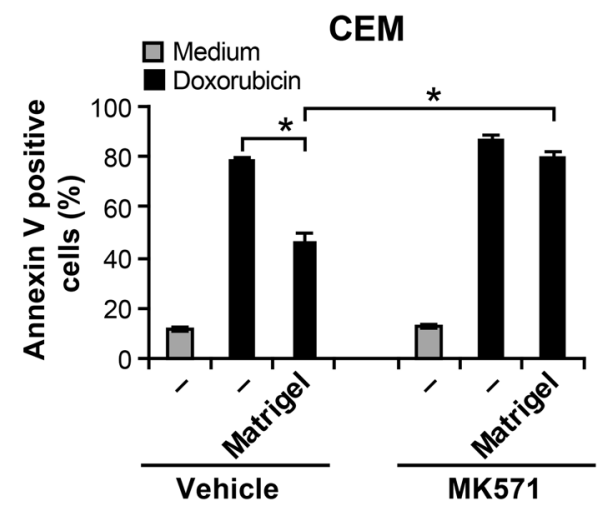

Jurkat
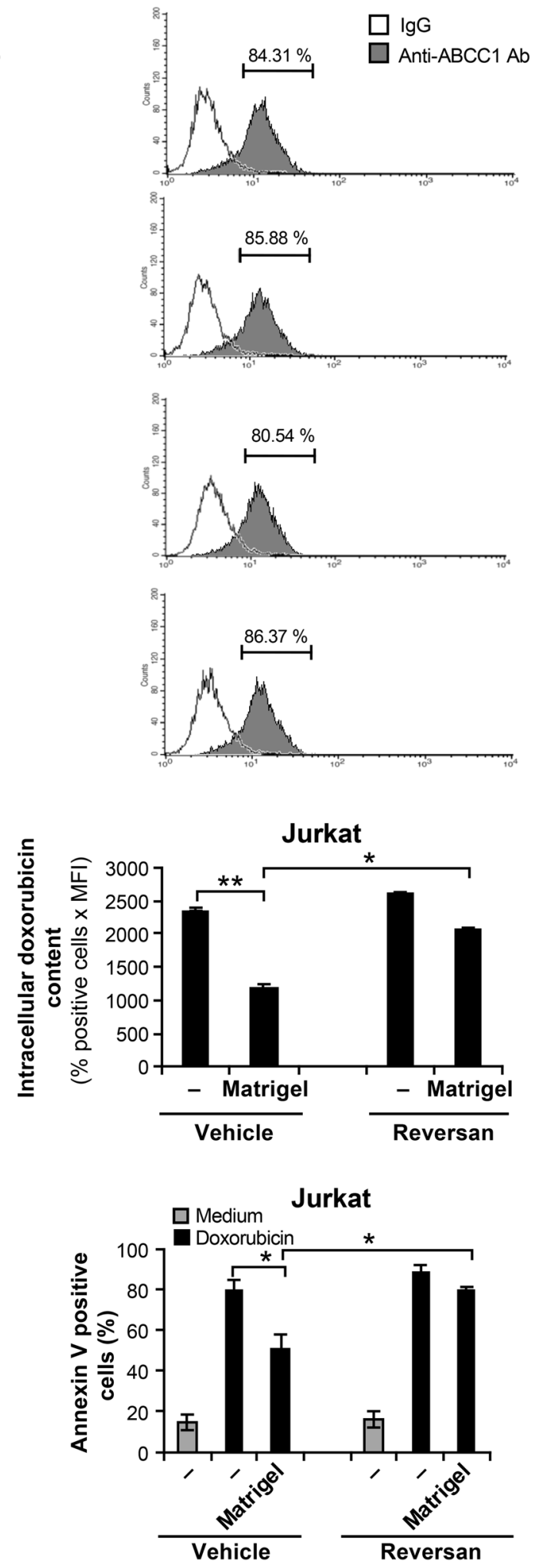

Fig. 5 (See legend on next page.) 
(see figure on previous page)

Fig. $\mathbf{5}$ Matrigel/ $\mathbf{\beta} 1$ integrin promotes doxorubicin resistance via $\mathbf{A B C C} 1$. a Expression levels of ABCC1 in CEM and Jurkat T cell lines as determined by flow cytometry (\% of positive cells is indicated). $\mathbf{b}$ ABCC1 inhibitors MK571 and reversan inhibit the ability of Matrigel to induce doxorubicin efflux. The cells were pre-treated with the vehicle as control or with $10 \mu \mathrm{M}$ of MK571 or reversan for $1 \mathrm{~h}$ and then cultured on plastic (-) or on Matrigel for $4 \mathrm{~h}$. The cells were then treated for $2 \mathrm{~h}$ with doxorubicin and the content of intracellular doxorubicin was determined by flow cytometry analysis. c The cells were pre-treated with inhibitors, cultured on Matrigel and treated with doxorubicin as above. Apoptosis was analyzed by annexin $V$ staining and flow cytometry after $24 \mathrm{~h}$ of treatment with doxorubicin. Results represent the mean values \pm S.D. from three independent experiments. ${ }^{*} P<0.05 ;{ }^{*} P<0.01$

acquired resistance to doxorubicin and the observed reduction in leukemic load is not sufficient to alleviate the leukemia burden. This finding is in line with a previous study, which reported resistance of CEM cells to chemotherapy when transplanted in immunocompromised mice $^{27}$. However, treatment with AIIB2 increased the effect of doxorubicin, further diminished bone marrow tumor load and extended animal survival indicating that $\beta 1$ integrin plays a major role in doxorubicin resistance. In contrast to chemoresistance, we found that inhibition of $\beta 1$ integrin with AIIB2 did not affect leukemic growth in the bone marrow but did so in the spleen. The role of $\beta 1$ integrins in T-ALL development and progression is still poorly addressed but this could be explained by the capacity of $\beta 1$ integrin to differentially sustain T-ALL growth in different hematologic sites or by the known role of $\beta 1$ integrin in metastasis and invasion of malignant $\mathrm{T}$ cells ${ }^{32,33}$. In this regard, $\alpha 4 \beta 1$ integrin is essential for $\mathrm{T}$ cell transendothelial migration and has been involved in $\mathrm{T}$ cell lymphoma metastasis to the spleen and other secondary lymphoid tissues ${ }^{34}$. Despite this effect, blockade of $\beta 1$ integrin had only a marginal effect on animal survival, which is likely due to the bone marrow disease that is not inhibited by the $\beta 1$ integrin blocking mAb AIIB2, indicating that $\beta 1$ integrin is dispensable for T-ALL growth in the bone marrow. Together these results propose an important role for $\beta 1$ integrin in T-ALL chemoresistance, which is supported by a clinical study showing that cell adhesion receptors of the $\beta 1$ integrin subfamily are the best predictors of patient relapse in pediatric T-ALL ${ }^{35}$. Thus, $\beta 1$ integrin is likely to constitute a major pathway and target in T-ALL chemoresistance.

Mechanistically, we found that $\beta 1$ integrin enhances TALL chemoresistance by activating drug efflux via the drug transporter $\mathrm{ABCC}$. This was shown both in vitro, and in vivo with the CEM xenograft model. These findings are likely to be of clinical significance since Matrigel/ $\beta 1$ integrin protects T-ALL blasts from doxorubicin (Fig. 2) and that ABCC1 is expressed in human T-ALL cells and its activity correlates with poor prognosis ${ }^{36,37}$.

$\beta 1$ integrin enhanced drug efflux not only in xenotransplanted CEM leukemic cells but also in mouse bone marrow cells (Fig. 4c). We did not investigate the identity of these cells but a recent study reported that $\beta 1$ integrin is important for the acquisition of side population (drug efflux and resistance to drugs) by hematopoietic stem progenitor cells ${ }^{38}$ suggesting that $\beta 1$ could be important for drug resistance of leukemia initiating cells via the activation of $\mathrm{ABC}$ transporters. Along these lines, $\beta 1$ integrin enhances mitoxantrone efflux in AML blasts upon their culture with mesenchymal stem cells ${ }^{38}$. Interestingly, mitoxantrone is a substrate for the drug transporter, $\mathrm{ABCG}$, whereas doxorubicin is a substrate for $A B C C 1$. Thus, together these studies strongly suggest that $\beta 1$ integrin-mediated activation of $\mathrm{ABC}$ transporters can be a major pathway in drug resistance of hematological malignancies.

We found that Matrigel did not increase $\mathrm{ABCC} 1$ expression levels indicating that its effect occurs likely at the activation level. In this regard, it has been shown that actin polymerization is required for the localization, stability and function of $\mathrm{ABCC}^{39}$. Accordingly, in our cell model, T-ALL cell interaction with Matrigel can lead to $\beta 1$ integrin-mediated actin polymerization, which then enhances $\mathrm{ABCC} 1$ activity. The mechanisms involved in $\mathrm{ABCC} 1$ activity are not well understood and factors such as receptor cycling and increased ATP production, which are required for the function of $A B C$ transporters, could also be involved in $\beta 1$ integrin-mediated $\mathrm{ABCC} 1$ activation.

Finally, we showed that $\beta 1$ integrin-mediated doxorubicin efflux and resistance in T-ALL cells involves PYK2. PYK2 is a member of the FAK family tyrosine kinase and has been associated with $\mathrm{T}$ cell signaling and cell migration downstream of integrins ${ }^{40}$. Our results indicate that inhibition of PYK2 reverses the effect of Matrigel on doxorubicin efflux and chemoresistance. A recent study also showed the implication of PYK2 in IL-6-dependant chemoresistance of ovarian cancer cells ${ }^{41}$. Thus, these studies suggest that PYK2 could play a crucial role in the tumor microenvironment-mediated cancer chemoresistance. The uncovered implication of PYK2 in T-ALL chemoresistance coupled with its reported role in myeloma cell survival and progression $^{42-44}$ suggest that PYK2 could represent an important target in hematological malignancies.

In summary, we report the first study to our knowledge, indicating that targeting $\beta 1$ integrin could constitute a therapeutic target in T-ALL. Doxorubicin is an important chemotherapeutic drug in the treatment of T-ALL and 

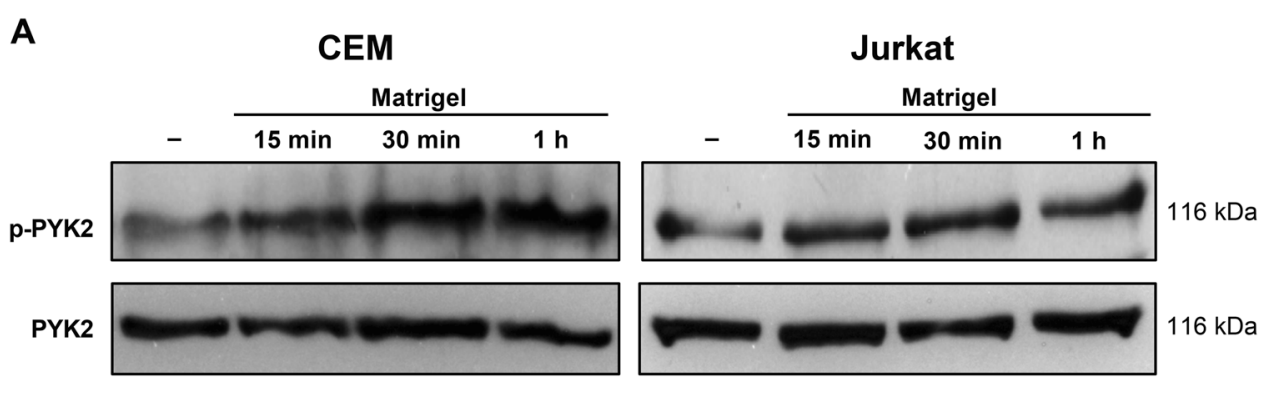

B
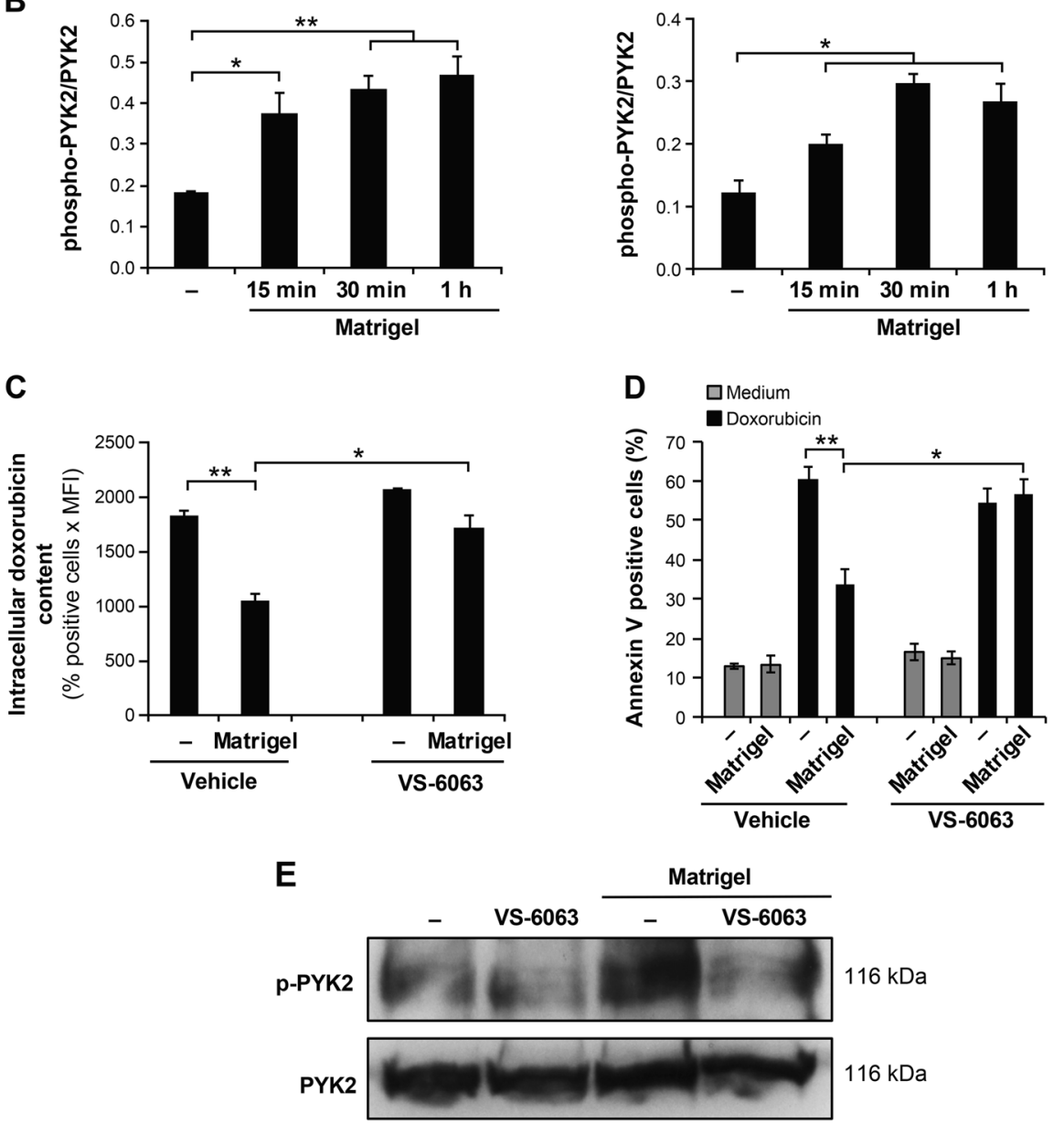

Fig. 6 Matrigel/ $\beta 1$ integrin-mediated doxorubicin resistance is dependent on PYK2. a Attachment to Matrigel increases PYK2 activation. CEM and Jurkat cells were cultured on Matrigel for the indicated periods of time. The cells were lysed and cell lysates subjected to immunoblot analysis using anti-phosphorylated PYK2 (Tyr-402) antibody. The blots were stripped and reprobed with anti-PYK2 antibody for equal loading. $\mathbf{b}$ Histograms represent densitometric quantification of PYK2 activation. The results are expressed as ratios between phosphorylated PYK2 (p-PYK2) and total PYK2. c The PYK2 inhibitor VS-6063 inhibits the effect of Matrigel in CEM T-ALL cell line. CEM cells were pre-treated for $1 \mathrm{~h}$ with the vehicle or with $0.5 \mu \mathrm{M}$ of VS-6063, cultured on plastic (-) or on Matrigel for $4 \mathrm{~h}$ and then treated with doxorubicin for $2 \mathrm{~h}$. Intracellular doxorubicin content was then determined by flow cytometry. $\mathbf{d}$ CEM cells were pre-treated with VS-6063, cultured on Matrigel and then treated with doxorubicin for $24 \mathrm{~h}$. Apoptosis was then analyzed by annexin V staining and flow cytometry. e VS-6063 inhibits Matrigel-induced PYK2 activation in CEM cells. The blot is representative of three independent experiments. Results represent the mean values \pm S.D. of three independent experiments. ${ }^{*} P<0.05$; ${ }^{* *} P<0.01$

our data suggest that blocking the $\beta 1$ integrin pathway could enhance its effect and may thus prevent relapse. Deeper knowledge on $\beta 1$ integrin signaling in T-ALL cells will likely lead to new insights in cell adhesion-mediated drug resistance and to the identification of additional therapeutic targets. 


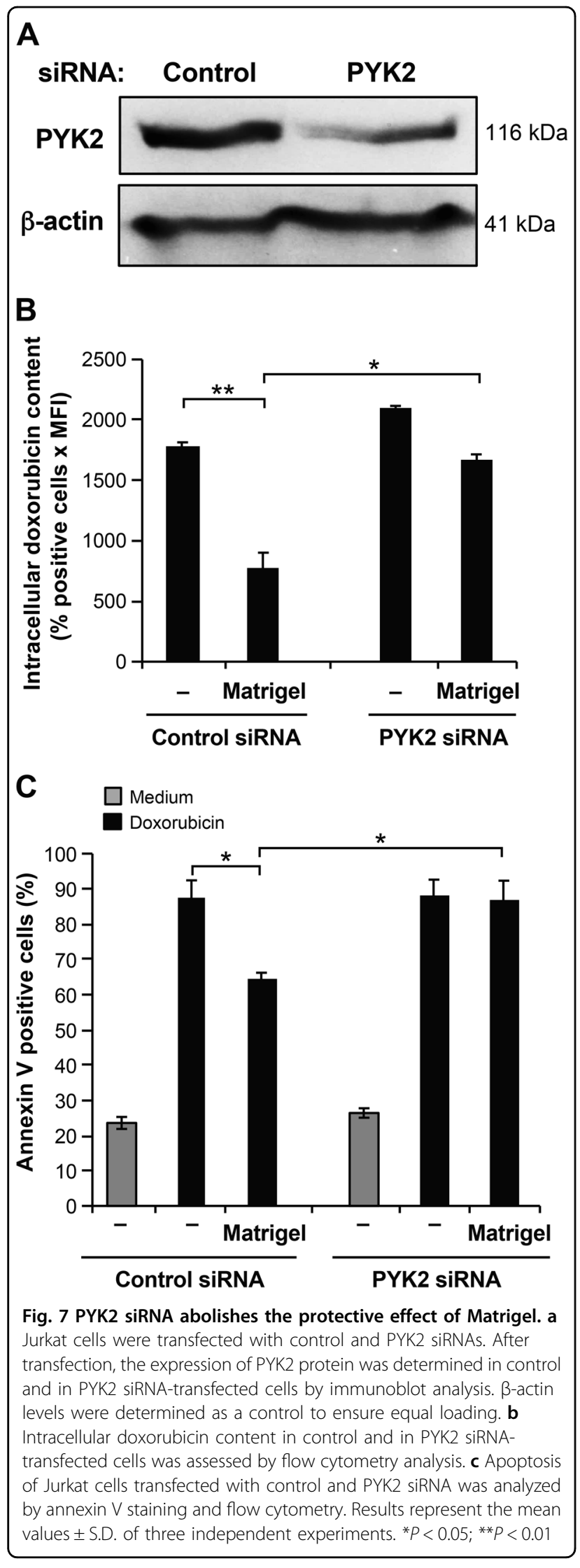

\section{Materials and methods}

Reagents and antibodies

Growth Factor Reduced Matrigel matrix was purchased from Corning (New York, NY). Doxorubicin and vincristine were from Millipore-Sigma (St-Louis, MO). The PYK2 inhibitor, VS-6063, was purchased from Cayman Chemicals (Ann Arbor, MI). ABCC1 inhibitors, MK571 and reversan, were from Millipore-Sigma (St-Louis, MO) and Tocris-Biotech Canada (Oakville, ON) respectively. The human $\beta 1$ integrin-specific blocking mAb AIIB2 (rat IgG1), which specifically binds to the $\beta 1$ integrin extracellular domain ${ }^{45,46}$, was prepared from a hybridoma cell line (Developmental Studies Hybridoma Bank of University of Iowa, Iowa, IA). Its control rat non-specific isotypic antibody was purchased from Santa Cruz Biotechnologies (Santa Cruz, CA). The blocking anti-mouse $\beta 1$ integrin $\mathrm{mAb}(\mathrm{Ha} 2 / 5)$ and its related control IgG were purchased from BD Biosciences (San Diego, CA). Antiphospho PYK2 (Tyr-402) and anti-PYK2 antibodies were purchased from Cell Signaling Technology, Inc (Danvers, $\mathrm{MA}$ ). Anti-caspase-3 (E-8) recognizing the native and active fragments of caspase- 3 , and anti- $\beta$-actin (C2) antibodies were from Santa Cruz Biotechnology (Santa Cruz, CA). FITC-conjugated anti-human ABCC1 (QCRL-3), PEand Alexa 647-conjugated anti-human CD5 (UCHT2), the APC-conjugated anti-human $\beta 1$ integrin (Mar4), control isotypic antibodies and FITC-conjugated Annexin V were purchased from BD Biosciences (San Diego, CA).

\section{Cell culture and primary blasts}

The human T-ALL cell lines Jurkat (E6.1), CCRF-CEM, HSB-2 and Molt-3 were from ATCC (Manassas, VA) and were cultured in RPMI 1640 medium containing 10\% of fetal bovine serum, 100 units $/ \mathrm{ml}$ penicillin and streptomycin, and $2 \mathrm{mmol} / \mathrm{l}$ glutamine (complete medium).

T-ALL patients were diagnosed and treated at Hôpital Saint-Louis (Paris, France). The patients or relatives have signed the consent forms according to the Declaration of Helsinki. Hôpital Saint-Louis and Institut Universitaire d'Hématologie Institutional Review Board approved the study. The study was performed with cryopreserved leukemic cells isolated from the blood of three stage IV T-ALL patients at diagnosis.

\section{Determination of apoptosis and clonogenic survival}

T-ALL cells $\left(10^{6} / \mathrm{ml}\right)$ in RPMI 1640 were cultured for $4 \mathrm{~h}$ on top of $8 \mathrm{mg} / \mathrm{ml}$ of Growth Factor Reduced Matrigel. The medium was then discarded and the cells were treated with doxorubicin in RPMI 1640 complete medium for $24 \mathrm{~h}$. T cell lines and T-ALL primary blasts were treated with 150 and $400 \mathrm{ng} / \mathrm{ml}$ of doxorubicin respectively. After drug treatment, apoptosis was analyzed by annexin V staining and flow cytometry using the FACSCalibur cytometer (BD Biosciences). 
For clonogenic survival assays, the cells were cultured on plastic or on Matrigel for $4 \mathrm{~h}$ and then treated with doxorubicin for $24 \mathrm{~h}$. The cells were recovered, washed and then seeded at $1 \times 10^{4}$ cells $/ \mathrm{ml}$ in complete medium with $1 \%$ methylcellulose (StemCell Technologies, Vancouver, BC). After 21 days, colonies with $>50$ cells were counted.

\section{T cell leukemia xenograft and animal protocol}

All procedures involving animals were conducted according to the requirements of and with the approval of the Laval University animal protection committee. We used the well-described human T-ALL CEM xenograft model, which involves bone marrow disease and other $\mathrm{T}$ ALL target organs such as the spleen ${ }^{26,27}$. NOD/SCID mice were purchased from Charles River Laboratories (Wilmington, MA) and used at eight weeks old. They were injected i.v. with $10^{7}$ of CEM cells and five days later, they were randomly divided into four groups and treated for three weeks with control IgG, blocking anti-human $\beta 1$ integrin $\mathrm{mAb}$ AIIB2, IgG + doxorubicin and AIIB2 + doxorubicin. Antibodies (10 mg/kg of body weight) were administered i.p. twice a week, whereas doxorubicin was administered i.p. once a week ( $1 \mathrm{mg} / \mathrm{kg}$ of body weight) and was given one day after the second injection of antibodies. Mice were observed regularly for signs of leukemia and moribund mice were sacrificed. Animal survival was assessed until mice became moribund and was analyzed by generating Kaplan-Meyer curves. Bone marrows were harvested and total cellular suspensions were prepared after red blood lysis. The cellular suspensions were then labeled with anti-human CD5 mAb and analyzed by flow cytometry (FACSCalibur II) for the determination of tumor load.

\section{Expression of integrins, $A B C C 1$ drug transporter and flow cytometry}

The cells were labeled with conjugated control or with specific antibodies against integrins and CD5 for $40 \mathrm{~min}$ at $4{ }^{\circ} \mathrm{C}$. For $\mathrm{ABCC} 1$ expression, we first permeabilized and fixed the cells with a cytoFix/CytoPerm kit (BD Biosciences) for $30 \mathrm{~min}$ at $4{ }^{\circ} \mathrm{C}$, after which, we incubated them with FITC-conjugated isotypic control or anti-ABCC1 antibodies. After antibody staining, the cells were washed and analyzed for integrin, $\mathrm{CD} 5$ and $\mathrm{ABCC} 1$ expression levels by flow cytometry using BD FACSCalibur II cytometer, and a Canto II flow cytometer (BD Biosciences) for the analysis of $\beta 1$ integrin on T-ALL blasts.

\section{Western blot analysis, caspase-3 and PYK2 activation}

Activation of caspase- 3 and PYK2 was determined by immunoblot analysis as we previously described ${ }^{47}$. After treatment, the cells were harvested, lysed in RIPA buffer and cell lysates subjected to immunoblot analysis using anticaspase-3 and anti-phospho-PYK2 (Tyr 402) antibodies.
The blots were stripped and reprobed with anti- $\beta$-actin or anti-PYK2 antibodies for loading control.

\section{Flow cytometry analysis of intracellular drug content}

Jurkat and CEM cells in RPMI 1640 medium were cultured on plastic or Matrigel for $4 \mathrm{~h}$ and then treated with doxorubicin in complete RPMI 1640 medium for $2 \mathrm{~h}$ at $37^{\circ} \mathrm{C}$. The cells were washed three times with PBS and doxorubicin intracellular content was analyzed by flow cytometry (FACSCalibur; BD Biosciences, San Diego, $\mathrm{CA})$. Doxorubicin fluorescence was detected using the FL2 channel. The data are presented as the percentage of positive cells times (x) MFI (mean fluorescence intensity) as previously described ${ }^{48-50}$.

\section{PYK2 siRNA and silencing}

Jurkat $\mathrm{T}$ cells $\left(5 \times 10^{6}\right)$ were transfected by the Nucleofector method (program C-016; Amaxa Biosystems, Cologne, Germany) with validated siRNA (mix of four sequences) directed against human PYK2 (103485) or with a related non-silencing control siRNA (ThermoFisher Scientific) as we previously described ${ }^{19}$. The cells were then transferred to pre-warmed complete medium and were used $24 \mathrm{~h}$ post-transfection in subsequent experiments. The efficiency of PYK2 silencing was assessed by western blot analysis.

\section{Statistical analysis}

Statistical analysis was performed by the Student's t-test (two-tailed, two samples equal variance). Significance of Kaplan-Meyer survival curves was determined by the logrank test. $P$-values $<0.05$ were considered significant.

\section{Acknowledgements}

This work was supported by a grant (MOP-136819) from the Canadian Institutes of Health Research to F.A. We thank Dr Amna Abderrazak (Université Laval) for critical reading of the manuscript.

\section{Author details}

${ }^{1}$ Division of Immune and Infectious Diseases, CHU de Québec-Université Laval Research Center, Quebec city, Canada. ${ }^{2} \mathrm{CHUM}$ Research Center and Faculty of Medicine, Université de Montréal, Montreal, Canada. ${ }^{3}$ Hôpital St-Louis, INSERM Unit 976, Université Paris-Diderot, Paris, France. ${ }^{4}$ Department of Medicine, Faculty of Medicine, Université Laval, Quebec city, Canada. ${ }^{5}$ Department of Microbiology-infectious Diseases and Immunology, Faculty of Medicine, Université Laval, Quebec city, Canada

Conflict of interests

The authors declare that they have no conflict of interests.

Publisher's note

Springer Nature remains neutral with regard to jurisdictional claims in published maps and institutional affiliations.

Supplementary Information accompanies this paper at (https://doi.org/ 10.1038/s41419-019-1593-2).

Received: 30 January 2019 Revised: 9 April 2019 Accepted: 12 April 2019 Published online: 01 May 2019 


\section{References}

1. Pui, C. H., Mullighan, C. G., Evans, W. E. \& Relling, M. V. Pediatric acute lymphoblastic leukemia: where are we going and how do we get there? Blood 120, 1165-1174 (2012).

2. Chiarini, F. et al. Advances in understanding the acute lymphoblastic leukemia bone marrow microenvironment: from biology to therapeutic targeting. Biochim. Biophys. Acta. 1863, 449-463 (2016).

3. Schepers, K., Campbell, T. B. \& Passegue, E. Normal and leukemic stem cell niches: insights and therapeutic opportunities. Cell Stem Cell 16, 254-267 (2015).

4. Humphries, J. D., Chastney, M. R., Askari, J. A. \& Humphries, M. J. Signal transduction via integrin adhesion complexes. Curr. Opin. Cell Biol. 56, 14-21 (2018).

5. Meads, M. B., Hazlehurst, L. A. \& Dalton, W. S. The bone marrow microenvironment as a tumor sanctuary and contributor to drug resistance. Clin. Cancer Res. 14, 2519-2526 (2008).

6. Eke, I. \& Cordes, N. Focal adhesion signaling and therapy resistance in cancer. Semin. Cancer Biol. 31, 65-75 (2015).

7. Aoudjit, F. \& Vuori, K. Integrin signaling in cancer cell survival and chemoresistance. Chemother. Res. Pract. 2012, 283181 (2012).

8. Emmons, M. F. et al. Acquisition of resistance toward HYD1 correlates with a reduction in cleaved alpha4 integrin expression and a compromised CAM-DR phenotype. Mol. Cancer Ther. 10, 2257-2266 (2011).

9. Noborio-Hatano, K. et al. Bortezomib overcomes cell-adhesion-mediated drug resistance through downregulation of VLA-4 expression in multiple myeloma. Oncogene 28, 231-242 (2009).

10. Damiano, J. S., Cress, A. E., Hazlehurst, L. A., Shtil, A. A. \& Dalton, W. S. Cell adhesion mediated drug resistance (CAM-DR): role of integrins and resistance to apoptosis in human myeloma cell lines. Blood 93, 1658-1667 (1999).

11. Bulian, P. et al. CD49d is the strongest flow cytometry-based predictor of overall survival in chronic lymphocytic leukemia. J. Clin. Oncol. 32, 897-904 (2014).

12. Hsieh, Y. T. et al. Integrin alpha4 blockade sensitizes drug resistant pre-B acute lymphoblastic leukemia to chemotherapy. Blood 121, 1814-1818 (2013).

13. Jacamo, R. et al. Reciprocal leukemia-stroma VCAM-1NLA-4-dependent activation of NF-kappaB mediates chemoresistance. Blood 123, 2691-2702 (2014).

14. Damiano, J. S., Hazlehurst, L. A. \& Dalton, W. S. Cell adhesion-mediated drug resistance (CAM-DR) protects the K562 chronic myelogenous leukemia cell line from apoptosis induced by BCR/ABL inhibition, cytotoxic drugs, and gamma-irradiation. Leukemia 15, 1232-1239 (2001).

15. Matsunaga, $T$. et al. Combination therapy of an anticancer drug with the FNIII14 peptide of fibronectin effectively overcomes cell adhesion-mediated drug resistance of acute myelogenous leukemia. Leukemia 22, 353-360 (2008).

16. Estrugo, D. et al. Ligand bound beta1 integrins inhibit procaspase-8 for mediating cell adhesion-mediated drug and radiation resistance in human leukemia cells. PLoS One 2, e269 (2007)

17. Ivanoff, J., Talme, T. \& Sundqvist, K. G. The role of chemokines and extracellular matrix components in the migration of $\mathrm{T}$ lymphocytes into three-dimensional substrata. Immunology 114, 53-62 (2005).

18. Chan, B. M., Wong, J. G., Rao, A. \& Hemler, M. E. T cell receptor-dependent, antigen-specific stimulation of a murine $T$ cell clone induces a transient, VLA protein-mediated binding to extracellular matrix. J. Immunol. 147, 398-404 (1991).

19. Naci, D. et al. alpha2beta1 integrin promotes chemoresistance against doxorubicin in cancer cells through extracellular signal-regulated kinase (ERK). J. Biol. Chem. 287, 17065-17076 (2012).

20. Liu, C. C., Leclair, P., Yap, S. Q. \& Lim, C. J. The membrane-proximal KXGFFKR motif of alpha-integrin mediates chemoresistance. Mol. Cell Biol. 33, 4334-4345 (2013).

21. Nilsson, S. K. et al. Immunofluorescence characterization of key extracellular matrix proteins in murine bone marrow in situ. J. Histochem. Cytochem. 46, 371-377 (1998).

22. Pitt, L. A. et al. CXCL12-Producing Vascular Endothelial Niches Control Acute T Cell Leukemia Maintenance. Cancer Cell 27, 755-768 (2015).

23. Passaro, D. et al. CXCR4 is required for leukemia-initiating cell activity in T cell acute lymphoblastic leukemia. Cancer Cell 27, 769-779 (2015).

24. Park, C. C., Zhang, H. J., Yao, E. S., Park, C. J. \& Bissell, M. J. Beta1 integrin inhibition dramatically enhances radiotherapy efficacy in human breast cancer xenografts. Cancer Res. 68, 4398-4405 (2008).

25. Dickreuter, E. et al. Targeting of beta1 integrins impairs DNA repair for radiosensitization of head and neck cancer cells. Oncogene 35, 1353-1362 (2016).

26. Li, Z. et al. Inhibition of IRAK1/4 sensitizes T cell acute lymphoblastic leukemia to chemotherapies. J. Clin. Invest. 125, 1081-1097 (2015).
27. Hosler, G. A., Bash, R. \& Scheuermann, R. H. Kinetics of early therapeutic response as measured by quantitative PCR predicts survival in a murine xenograft model of human T cell acute lymphoblastic leukemia. Leukemia 14, 1215-1224 (2000).

28. Robey, R. W. et al. Revisiting the role of $A B C$ transporters in multidrug-resistant cancer. Nat. Rev. Cancer. 18, 452-464 (2018).

29. van der Heijden, J. et al. Development of sulfasalazine resistance in human $T$ cells induces expression of the multidrug resistance transporter ABCG2 (BCRP) and augmented production of TNFalpha. Ann. Rheum. Dis. 63, 138-143 (2004).

30. Hammond, C. L., Marchan, R., Krance, S. M. \& Ballatori, N. Glutathione export during apoptosis requires functional multidrug resistance-associated proteins. J Biol Chem 282, 14337-14347 (2007).

31. Hawkins, E. D. et al. T-cell acute leukaemia exhibits dynamic interactions with bone marrow microenvironments. Nature 538, 518-522 (2016).

32. Ivanoff, A., Ivanoff, J., Hultenby, K. \& Sundqvist, K. G. Infiltrative capacity of T leukemia cell lines: a distinct functional property coupled to expression of matrix metalloproteinase-9 (MMP-9) and tissue inhibitor of metalloproteinases-1 (TIMP-1). Clin. Exp. Metastasis. 17, 695-711 (1999).

33. Vadillo, E., Dorantes-Acosta, E., Pelayo, R. \& Schnoor, M. T cell acute lymphoblastic leukemia (T-ALL): New insights into the cellular origins and infiltration mechanisms common and unique among hematologic malignancies. Blood. Rev. 32, 36-51 (2018).

34. Singh, V., Erb, U. \& Zoller, M. Cooperativity of CD44 and CD49d in leukemia cell homing, migration, and survival offers a means for therapeutic attack. J. Immunol. 191, 5304-5316 (2013).

35. Cleaver, A. L. et al. Gene-based outcome prediction in multiple cohorts of pediatric T-cell acute lymphoblastic leukemia: a Children's Oncology Group study. Mol. Cancer 9, 105 (2010).

36. Winter, S. S. et al. ATP Binding Cassette C1 (ABCC1/MRP1)-mediated drug efflux contributes to disease progression in T-lineage acute lymphoblastic leukemia. Health. https://doi.org/10.4236/health.2013.55A005. (2013).

37. Plasschaert, S. L. et al. Expression of multidrug resistance-associated proteins predicts prognosis in childhood and adult acute lymphoblastic leukemia. Clin. Cancer Res. 11, 8661-8668 (2005).

38. Malfuson, J. V. et al. SP/drug efflux functionality of hematopoietic progenitors is controlled by mesenchymal niche through VLA-4/CD44 axis. Leukemia $\mathbf{2 8}$, 853-864 (2014).

39. Hummel, I., Klappe, K., Ercan, C. \& Kok, J. W. Multidrug resistance-related protein 1 (MRP1) function and localization depend on cortical actin. Mol. Pharmacol. 79, 229-240 (2011)

40. Chapman, N. M. \& Houtman, J. C. Functions of the FAK family kinases in T cells: beyond actin cytoskeletal rearrangement. Immunol. Res. 59, 23-34 (2014).

41. Pasquier, J. et al. CCL2/CCL5 secreted by the stroma induce IL-6/PYK2 dependent chemoresistance in ovarian cancer. Mol. Cancer 17, 47 (2018).

42. Kamihara, $Y$. et al. The iron chelator deferasirox induces apoptosis by targeting oncogenic Pyk2/beta-catenin signaling in human multiple myeloma. Oncotarget 7, 64330-64341 (2016).

43. Zhang, Y. et al. Pyk2 promotes tumor progression in multiple myeloma. Blood 124, 2675-2686 (2014).

44. Meads, M. B. et al. Targeting PYK2 mediates microenvironment-specific cell death in multiple myeloma. Oncogene 35, 2723-2734 (2016).

45. Hall, D. E. et al. The alpha 1/beta 1 and alpha 6/beta 1 integrin heterodimers mediate cell attachment to distinct sites on laminin. J. Cell Biol. 110, 2175-2184 (1990).

46. Tomaselli, K. J., Damsky, C. H. \& Reichardt, L. F. Purification and characterization of mammalian integrins expressed by a rat neuronal cell line (PC12): evidence that they function as alpha/beta heterodimeric receptors for laminin and type IV collagen. J. Cell Biol. 107, 1241-1252 (1988).

47. Naci, D. \& Aoudjit, F. Alpha2beta1 integrin promotes T cell survival and migration through the concomitant activation of ERK/Mcl-1 and p38 MAPK pathways. Cell Signal. 26, 2008-2015 (2014).

48. Abderrazak, A., El Azreq, M. A., Naci, D., Fortin, P. R. \& Aoudjit, F. Alpha2beta1 integrin (VLA-2) protects activated human effector T cells from methotrexateinduced apoptosis. Front. Immunol. 9, 2269 (2018).

49. Darrah, P. A. et al. Multifunctional TH1 cells define a correlate of vaccinemediated protection against Leishmania major. Nat. Med. 13, 843-850 (2007).

50. Han, L. et al. Single-cell STAT5 signal transduction profiling in normal and leukemic stem and progenitor cell populations reveals highly distinct cytokine responses. PLoS One 4, e7989 (2009). 